\title{
ANALISIS NILAI TAMBAH PERMEN AIR KELAPA
}

\author{
Hermiza Mardesci, S.TP., MP \\ Program Studi Teknologi Pangan Universitas Islam Indragiri. Jalan Lintas Provinsi \\ Parit 1, Tembilahan, Indragiri Hilir \\ mimzaaci@yahoo.co.id
}

\begin{abstract}
Abstrak
Penelitian ini bertujuan untuk mengetahui nilai tambah permen air kelapa. Penelitian dilakukan di salah satu UMKM di Indragiri Hilir yang memproduksi permen air kelapa. Analisis data dilakukan dengan menggunakan metode Hayami. Berdasarkan hasil penelitian, dapat ditarik kesimpulan bahwa pengolahan air kelapa menjadi permen air kelapa dapat meningkatkan nilai tambah. Nilai tambah produk permen air kelapa ini sebesar Rp. 69.980,8 per kg, dengan rasio nilai tambah sebesar 70\%. Nilai tambah ini masuk kategori tinggi, karena lebih besar dari 40\%. Nilai tambah yang tinggi ini bisa meningkatkan kesejahteraan pengrajin permen air kelapa di Indragiri Hilir.
\end{abstract}

Kata Kunci : air kelapa, permen air kelapa, metode Hayami, nilai tambah produk

\section{PENDAHULUAN}

Kelapa merupakan komoditas pertanian yang banyak dihasilkan di Indragiri Hilir. Menurut data statistika, produksi kelapa dalam di Indragiri Hilir mencapai $265.874 .517 \mathrm{~kg}$ pada tahun 2017 (BPS 2019). Hampir semua bagian dari buah kelapa dapat dimanfaatkan, baik dari daging buah, air kelapa, tempurung, maupun hasil samping dari buah kelapa lainnya.

Tingginya produksi kelapa di Indragiri Hilir menyebabkan produksi air kelapa juga melimpah. Air kelapa dapat diolah menjadi beragam produk olahan untuk meningkatkan nilai tambah. Ada beberapa pilihan produk olahan yang bisa dihasilkan dari air kelapa, seperti nata de coco, kecap, sirup, permen, minuman isotonik, dan lain sebagainya (Mardesci, 2019). Pengolahan air kelapa menjadi produk yang bisa dipasarkan akan dapat meningkatkan nilai tambah. Salah satu produk yang cukup potensial dikembangkan adalah permen dari air kelapa. Hasil penelitian Jurait dan Mardesci (2016) menunjukkan bahwa permen dari air kelapa cukup disukai oleh konsumen di Indragiri Hilir.

Pengolahan air kelapa menjadi permen cukup menjanjikan, karena bisa meningkatkan nilai tambah produk. Secara tidak langsung bisa meningkatkan pendapatan pengrajin kelapa di Indragiri Hilir. Beberapa penelitian tentang nilai tambah produk olahan kelapa sudah banyak dilakukan, seperti nilai tambah pada kopra (Noviyanti et al. (2018), gula kelapa (Prasetyo et al. (2018), nata de coco (Wardanu dan Uliyanti (2015) atau produk lainnya. Namun penelitian 
mengenai nilai tambah produk permen dari air kelapa belum pernah dilakukan. Oleh sebab itu, penelitian ini bertujuan untuk menganalisis nilai tambah permen dari air kelapa sehingga diketahui seberapa besar nilai tambah dari $1 \mathrm{~kg}$ air kelapa yang diolah menjadi permen air kelapa.

\section{METODOLOGI PENELITIAN}

Penelitian dilakukan di salah satu UMKM di Indragiri Hilir yang bergerak dalam pengolahan air kelapa, yakni UMKM Rahmat Illahi yang terletak di Kecamatan Tembilahan Hulu, Indragiri Hilir. Pemilihan lokasi ini dilakukan secara sengaja karena UMKM ini memproduksi beberapa produk olahan dari air kelapa, yang salah satunya adalah permen kelapa.

Analisis data dilakukan dengan menggunakan metode Hayami (Hayami et al., 1987). Metode Hayami metode perhitungan nilai tambah yang dikembangkan oleh Hayami pada tahun 1987 dengan cara menggabungkan dua nilai tambah, yaitu nilai tambah pengolahan dan nilai tambah untuk pemasaran (Hidayat et al., 2012).. Template untuk metode Hayami dapat dilihat pada Tabel 1 .

Tabel 1. Template untuk Metode Hayami

\begin{tabular}{|c|c|c|}
\hline No & VARIABEL & NOTASI \\
\hline & Output dan Input & \\
\hline 1. & Hasil produksi (kg/hari) & A \\
\hline 2. & Bahan baku (kg/hari) & $\mathrm{B}$ \\
\hline 3. & Tenaga kerja (HOK/hari) & $\mathrm{C}$ \\
\hline 4. & Faktor konversi & $\mathrm{D}=\mathrm{A} / \mathrm{B}$ \\
\hline 5. & Koefisien tenaga kerja & $\mathrm{E}=\mathrm{C} / \mathrm{B}$ \\
\hline 6. & Harga produk rata-rata $(\mathrm{Rp} / \mathrm{kg})$ & $\mathrm{F}$ \\
\hline \multirow[t]{2}{*}{7.} & Upah rata-rata $(\mathrm{Rp} / \mathrm{HOK})$ & $\mathrm{G}$ \\
\hline & Pendapatan dan Keuntungan & \\
\hline 8. & Harga bahan baku (Rp/kg) & $\mathrm{H}$ \\
\hline 9. & Sumbangan input lain (Rp/kg) & $\mathrm{I}$ \\
\hline 10. & Nilai produk (Rp/kg) & $\mathrm{J}=\mathrm{D} * \mathrm{~F}$ \\
\hline \multirow[t]{2}{*}{11.} & a. Nilai tambah $(\mathrm{Rp} / \mathrm{kg})$ & $\mathrm{K}=\mathrm{J}-\mathrm{H}-\mathrm{I}$ \\
\hline & b. Rasio nilai tambah & $\mathrm{L}=\mathrm{K} / \mathrm{J} * 100 \%$ \\
\hline \multirow[t]{2}{*}{12.} & a. Imbalan tenaga kerja (Rp/HOK) & $\mathrm{M}=\mathrm{E}^{*} \mathrm{G}$ \\
\hline & b. Pangsa tenaga kerja & $\mathrm{N}=\mathrm{M} / \mathrm{K}^{*} 100 \%$ \\
\hline \multirow[t]{3}{*}{13.} & a. Keuntungan (Rp/kg) & $\mathrm{O}=\mathrm{K}-\mathrm{M}$ \\
\hline & b. Tingkat keuntungan & $\mathrm{P}=\mathrm{O} / \mathrm{K} * 100 \%$ \\
\hline & Balas Jasa Pemilik Faktor Produksi & \\
\hline \multirow[t]{4}{*}{14.} & Marjin $(\mathrm{Rp} / \mathrm{kg})$ & $\mathrm{Q}=\mathrm{J}-\mathrm{H}$ \\
\hline & a. Pendapatan tenaga kerja & $\mathrm{R}=\mathrm{M} / \mathrm{Q}^{*} 100 \%$ \\
\hline & b. Sumbangan input lain & $\mathrm{S}=\mathrm{I} / \mathrm{Q} * 100 \%$ \\
\hline & c. Keuntungan pengusaha & $\mathrm{T}=\mathrm{O} / \mathrm{Q} * 100 \%$ \\
\hline
\end{tabular}




\section{HASIL DN PEMBAHASAN}

Air kelapa merupakan salah satu bagian dari buah kelapa yang bisa diolah menjadi berbagai macam produk olahan. Diantara produk turunan kelapa yang dapat diolah dari air kelapa dan memiliki nilai tambah dibandingkan produk primer adalah nata de coco, sirup, permen, dan kecap (Wardanu dan Uliyanti, 2015); (Jurait dan Mardesci, 2016); (Yanti dan Asni, 2014); (Solang et al., 2017); (Kusumawardhani, 2011).

Menurut Buckle et al., (2009) dalam Jurait dan Mardesci (2016) permen adalah produk yang dihasilkan dengan cara mendidihkan campuran air dan gula, dengan pemberian pewarna dan bahan perasa sampai mencapai kadar air sekitar 3\%. Suhu yang digunakan berkisar antara $90-150^{\circ} \mathrm{C}$. Permen dari air kelapa, menggunakan air kelapa sebagai bahan bakunya.

Proses pengolahan air kelapa menjadi permen melibatkan bahan baku lain, seperti gula, dan lain sebagainya. Kebutuhan bahan baku dan bahan pendukung dalam pengolahan permen dapat di lihat pada Tabel 2. Selain dari bahan baku utama dan bahan baku penolong, biaya yang dikeluarkan juga mencakup upah tenaga kerja, dan kebutuhan utilitas industri lain, seperti air, listrik, dan gas. Tenaga kerja yang diperlukan untuk pengolahan permen adalah 5 orang.

Tabel 2. Kebutuhan dan Biaya Bahan Baku untuk Pengolahan Permen Air Kelapa

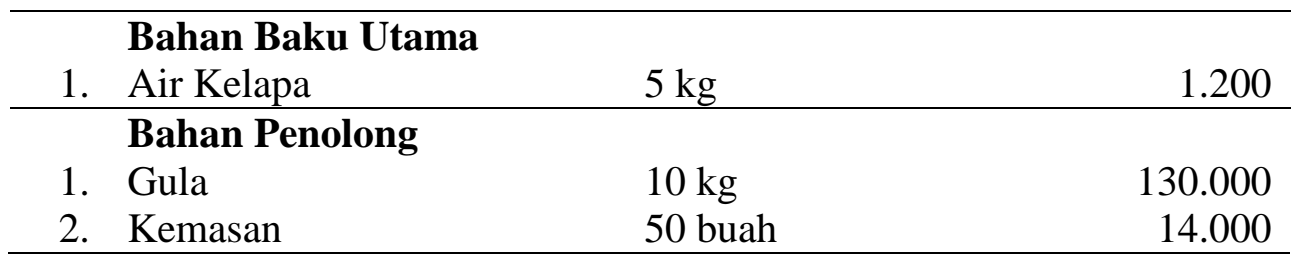

Upah tenaga kerja pada home industry air kelapa ini adalah Rp. 40.000,- per HOK. Sedangkan biaya listrik Rp. 100.000 per bulan, gas Rp. 250.000 per bulan, dan air Rp. 120.000 per bulan.

Perhitungan analisis nilai tambah air kelapa pada industri pengolahan air kelapa di Indragiri Hilir, dapat dilihat pada Tabel 3. Perhitungan ini menggunakan metode Hayami (Hayami et al., 1987).

Pada Tabel 3 dapat terlihat bahwa harga bahan baku air kelapa adalah $\mathrm{Rp}$. 240 per $\mathrm{kg}$, sedangkan harga output (permen) yang dijual oleh pengrajin adalah Rp. 5000 per kg. Harga jual ditetapkan sendiri oleh pengrajin dengan mempertimbangkan harga di pasaran. Upah tenaga kerja rata-rata pada usaha permen air kelapa ini adalah Rp. 40.000 per HOK.

Hasil perhitungan nilai tambah permen air kelapa sebesar Rp. 69.980,8 per $\mathrm{kg}$, dengan rasio nilai tambah sebesar 70\%. Hal ini berarti bahwa nilai tambah ini masuk kategori tinggi, karena berdasarkan kriteria Reyne (1987) dalam Arianti dan Waluyati (2019) nilai tambah dengan kategori tinggi adalah yang berada di atas $40 \%$. Perhitungan nilai tambah ini diperoleh dari pengurangan nilai produk dengan harga bahan baku dan sumbangan input lain. Nilai sumbangan input lain pada pengolahan permen air kelapa ini sebesar $30 \%$. Sumbangan input lain ini menyebabkan meningkatnya nilai tambah permen air kelapa. 
Tingkat keuntungan sebesar $43 \%$ merupakan hal yang cukup menjanjikan bagi pengrajin permen air kelapa. Keuntungan ini diperoleh dari pengolahan $1 \mathrm{~kg}$ air kelapa setelah dikurangi biaya produksi untuk satu kali proses pengolahan permen air kelapa. Hal ini dapat meningkatkan kesejahteraan pengrajin permen air kelapa.

Tabel 3. Perhitungan Nilai Tambah Permen Air Kelapa

\begin{tabular}{|c|c|c|}
\hline No & VARIABEL & NOTASI \\
\hline & Output dan Input & \\
\hline 1. & Hasil produksi (kg/hari) & 10 \\
\hline 2. & Bahan baku (kg/hari) & 5 \\
\hline 3. & Tenaga kerja (HOK/hari) & 5 \\
\hline 4. & Faktor konversi & 2 \\
\hline 5. & Koefisien tenaga kerja & 1 \\
\hline 6. & Harga produk rata-rata $(\mathrm{Rp} / \mathrm{kg})$ & 50000 \\
\hline \multirow[t]{2}{*}{7.} & Upah rata-rata $(\mathrm{Rp} / \mathrm{HOK})$ & 40000 \\
\hline & Pendapatan dan Keuntungan & \\
\hline 8. & Harga bahan baku (Rp/kg) & 240 \\
\hline 9. & Sumbangan input lain (Rp/kg) & 29779.2 \\
\hline 10. & Nilai produk (Rp/kg) & 100000 \\
\hline \multirow[t]{2}{*}{11.} & c. Nilai tambah $(\mathrm{Rp} / \mathrm{kg})$ & 69980.8 \\
\hline & d. Rasio nilai tambah & $70 \%$ \\
\hline \multirow[t]{2}{*}{12.} & c. Imbalan tenaga kerja (Rp/HOK) & 40000 \\
\hline & d. Pangsa tenaga kerja & $57 \%$ \\
\hline \multirow[t]{3}{*}{13.} & c. Keuntungan (Rp/kg) & 29980.8 \\
\hline & d. Tingkat keuntungan & $43 \%$ \\
\hline & Balas Jasa Pemilik Faktor Produksi & \\
\hline \multirow[t]{4}{*}{14.} & Marjin $(\mathrm{Rp} / \mathrm{kg})$ & 99760 \\
\hline & d. Pendapatan tenaga kerja & $40 \%$ \\
\hline & e. Sumbangan input lain & $30 \%$ \\
\hline & f. Keuntungan pengusaha & $30 \%$ \\
\hline
\end{tabular}

\section{KESIMPULAN DAN SARAN}

\section{Kesimpulan}

Berdasarkan hasil penelitian, dapat ditarik kesimpulan bahwa pengolahan air kelapa menjadi permen air kelapa dapat meningkatkan nilai tambah. Nilai tambah produk permen air kelapa ini sebesar Rp. 69.980,8 per $\mathrm{kg}$, dengan rasio nilai tambah sebesar $70 \%$. Nilai tambah ini masuk kategori tinggi, karena lebih besar dari $40 \%$.

\section{Saran}

Agar agroindustri pengolahan permen air kelapa makin meningkat, perlu strategi pengembangan untuk agroindustri tersebut. oleh sebab itu, perlu dilakukan penelitian lebih lanjut untuk mengetahui faktor-faktor yang mempengaruhi usaha permen air kelapa, dan strategi pengembangan yang cocok untuk UMKM di Indragiri Hilir. 


\section{DAFTAR PUSTAKA}

Arianti, Y.S. dan L.R. Waluyati. 2019. Analisis Nilai Tambah dan Strategi Pengembagan Agroindustri Gula Merah di Kabupaten Madiun. Jurnal Ekonomi Pertanian dan Agribisnis (JEPA) Vol.3 No. 2. Pp: 256-266.

BPS (Badan Pusat Statistik). 2019. Indragiri Hilir dalam Angka Tahun 2017. Tembilahan.

Hayami, Y., T. Kawagoe, Y. Morooka, and M. Siregar. 1987. Agricultural Marketing and Processing in Upland Java A Perspective from A Sunda Village. Bogor. CPGRT Centre.

Hidayat, S., Marimin, A. Suryani, Sukardi, dan M. Yani. 2012. Modifikasi Metode Hayami untuk Perhitungan Nilai Tambah pada Rantai Pasok Agroindustri Kelapa Sawit. Jurnal Teknologi Industri Pertanian. Vol. 22 No. 1. Pp: 2231.

Jurait, M. dan H. Mardesci, 2016. Studi Pembuatan Permen dari Air Kelapa terhadap Karakteristik dan Penerimaan Konsumen. Jurnal Teknologi Pertanian, Universitas Islam Indragiri Vol.5 No.1. Pp: 23-29.

Kusumawardhani, W. 2011. Pemanfaatan Air Kelapa sebagai Produk Olahan Kecap dengan Penambahan Bubuk Kedelai dan Bubuk Tempe [Skripsi]. Fakultas Pertanian. Surakarta, Universitas Sebelas Maret.

Mardesci, H. 2018. Diversifikasi dan Pengolahan Produk Olahan Berbasis Air Kelapa. Jurnal Teknologi Pertanian, Universitas
Islam Indragiri Vol. 7 No. 2. Pp: 45-50.

Noviyanti, S.R., T.Y.E. Shinta and Masliani. 2018. Analysis of Coconut Added Value to Copra in Pematang Kambat Village Seruyan Hilir Timur Subdistrict Seruyan District (A Case Study at Copra Udin Industry). Journal Socio Economics Agricultural (J-SEA) Vol. 13(2): 44-50.

Prasetiyo, D. B., A. W. Muhaimin and S. Maulidah. 2018. Analisis Nilai Tambah Nira Kelapa pada Agroindustri Gula Merah Kelapa (Kasus pada Agroindustri Gula Merah di Desa Karangrejo Kecamatan Garum, Blitar). Jurnal Ekonomi Pertanian dan Agribisnis (JEPA) Vol. 2 No.1. Pp: 45-51.

Solang, M., D. Lamondo, dan N.Y. Kandowangko. 2017. Diversifikasi Pengolahan Limbah Air Kelapa sebagai Produk Minuman Ramah Lingkungan untuk Pemberdayaan Petani desa Kaliyoso Kecamatan Dungaliyo Kabupaten Gorontalo. Gorontalo, Fakultas Matematika dan IPA, Universitas Negeri Gorontalo: 1-54.

Wardanu, A. P. dan Uliyanti. 2015. Analisa Nilai Tambah dan Kelayakan Agroindustri Nata de coco di Kabupaten Ketapang Kalimantan Barat. Jurnal Teknologi dan Industri Pertanian Indonesia Vol. 07 No.2. Pp: 44-47.

Yanti, L. dan N. Asni. 2014. Teknologi Pengolahan Sirup Kelapa Ramah Lingkungan untuk Pemberdayaan Petani di Lahan Pasang Surut Provinsi Jambi. Konferensi Nasional Kelapa VIII. 